\section{UNZIPPING A MEMBRANE}

Stephen W. Carmichael and Julio M. Fernandez ${ }_{1}{ }^{1}$ Mayo Clinic

The atomic force microscope (AFM) is well known for its outstanding spatial resolution, but it is becoming increasingly useful as the instrument for force spectroscopy. In the force spectroscopy mode, the AFM can measure tiny tension forces, in the piconewton $(\mathrm{pN}$ ) range. Daniel Müller, Wolfgang Baurmeister, and Andreas Engel have used the AFM in both the imaging and force spectroscopy modes to pull proteins out of membranes in a controlled fashion. ${ }^{2}$

Müller et al. used Deinococcus radiodurans, a bacterium best known for its high resistance to radiation (as its Genus name implies), as their test subject. They extracted a highly regular membrane from the bacterium, the hexagonally packed intermediate (HPI) layer. They mounted the HPI on mica, so that the hydrophilic outer surface of the HPI adsorbed strongly to the mica, exposing the hydrophobic inner surface to the silicon nitride AFM stylus. With the AFM in the contact imaging mode, they could clearly visualize what looked like a closelypacked group of circular pies, each pie cut into six equal pieces called protomers. At the center of the pie was a pore, whose diameter was controlled by the arrangement of the protomers.

After imaging the HPI with the AFM, Müller et al. brought the AFM stylus into contact with the specimen for one second, allowing the stylus to contact the protomers on the inner layer of the HPI. When the stylus stuck to a protomer on the inner surface, and the stylus was withdrawn, interesting measurements were made. In most cases, the force spectrograph showed a deflection of the stylus indicating a bond until the stylus was about $10 \mathrm{~nm}$ from the surface where the stylus sprang back indicating the bond had ruptured. To use our analogy, a piece of pie was picked up, but was dropped back into the pie before we got very far. In the remaining cases, three different spectro- graphs were seen. In the first case, a force peak of about $90 \mathrm{pN}$ was seen after retracting the stylus about $15 \mathrm{~nm}$, indicating that a molecular bridge was extended from the stylus to the surface. This is like a small thread was present that pulled our piece of pie back into the pie. In the second case, a force peak closer to 300 $\mathrm{pN}$ was measured, about three times higher than the first case when the protomer detached from the stylus and was pulled back into the hexagon by the molecular bridge. After this measurement, the follow up image made with the AFM showed a protomer was missing (follow up images after the other measurements did not show any changes). The thread connected to our piece of pie had been broken, and the piece was extracted from the pie. But the best is yet to come.

The third type of force spectrograph is the most amazing. There were up to six equally spaced peaks in the 200-300 pN range, with the peak-to-peak distance corresponding to about 7.3 $\mathrm{nm}$. So we have picked up a piece of pie to find each piece of pie threaded together, occasionally allowing us to pick up the entire pie, piece by piece. Múller et al. referred to this as "controlled unzipping." This demonstrates the ability of the AFM to not only measure intermolecular forces, but to also directly visualize and correlate the resulting structural changes.

With current techniques it is difficult to study the structure of membrane proteins. The novel approach demonstrated by Müller et al. greatly increases our ability to examine the structural features of membrane proteins in situ. It will not be long until the single molecule AFM technique demonstrated in this article can monitor the conformational changes of ion channels and receptors during their physiological activity.

1. The authors gratefully acknowledge Dr. Andreas Engel for reviewing this article.

2. Müller, D.J., W. Baumeister, and A. Engel, Controlled unzipping of a bacterial surface layer with atomic force microscopy, Proc. Nat. Acad. Sci. USA 96:13170-13174, 1999.

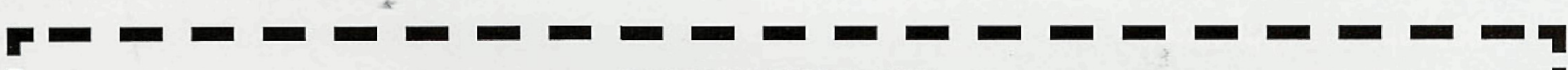 \\ INDEX OF ARTICLES
}

Unzipping A Membrane.....

Stephen W. Carmichael \& Julio M. Fernandez,

Mayo Clinic

M\&M 2000 EXPERT'S SESSION ON FACILITY MANAGEMENT-PART 2

Debby Sherman (Organizer), Purdue University

The Use Of Ultrarapid Freezing And Freeze Substitution.......16 To Verify Vitrification And/Or Iced Formation In Vascular

Tissue

Fred Lightfoot, Michael Taylor \& Kelvin G.M. Brockbank,

Organ Recovery Systems, Inc. and Cindy Hastings,

Central Arkansas Veterans Healthcare Systems

Energy-Filtered Imaging .22

J. Bentley, Oak Ridge National Laboratory

The Energy Spectra Of Secondary Electrons... .26

David Joy, Oak Ridge National Laboratory and

David Braski, University of Tennessee
3 A Commentary On Immunolabeling Paul Webster, House Ear Institute

LR White Flat Embedding of Cells Grown on Coverslips........34 Tamara Howard, Cold Spring Harbor Laboratory

Resolution and Resolving Power. 36 Ron Anderson, IBM Company

Safe Disposal of Mercury Salts .36 Bryan D. Llewellyn, Prince George Regional Hospital

Cleaning Platinum Crucibles 36 Wilbur C. Bigelow, University of Michigan

Preparing Diatoms for EM 36 Greg Strout, University of Oklahoma

Preparing Powders For Electron Diffraction Studies..............37 Scott D. Walck, PPG Industries, Inc.

A Tip on Purifying Glutaraldehyde.... 37

Lawrence R. Melsen,

Emory University School of Medicine 


\section{Ileed
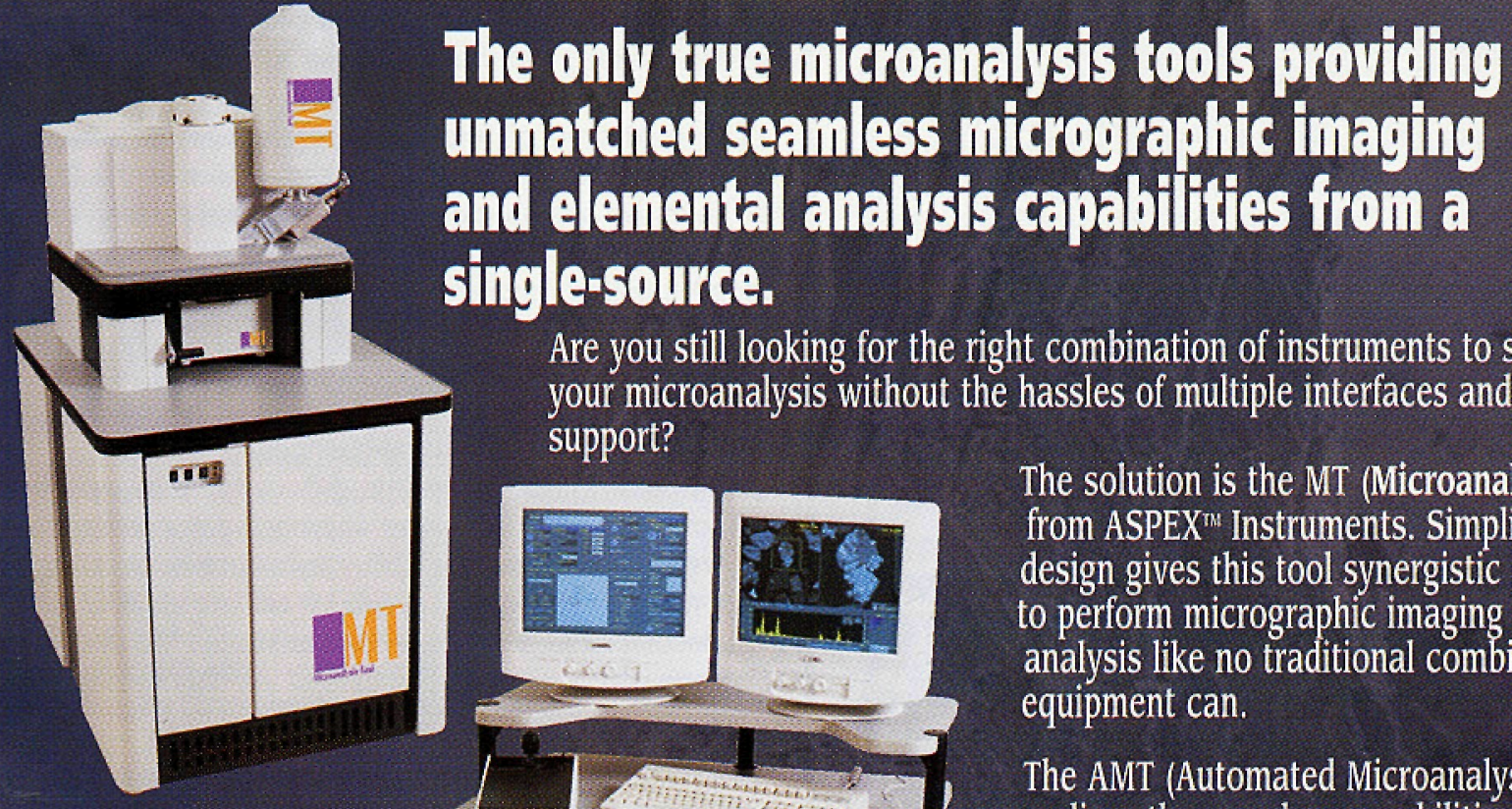

Are you still looking for the right combination of instruments to simplify your microanalysis without the hassles of multiple interfaces and proprietary support?

Both the Aliri and wir can be customized to meet spectific application requitrements.
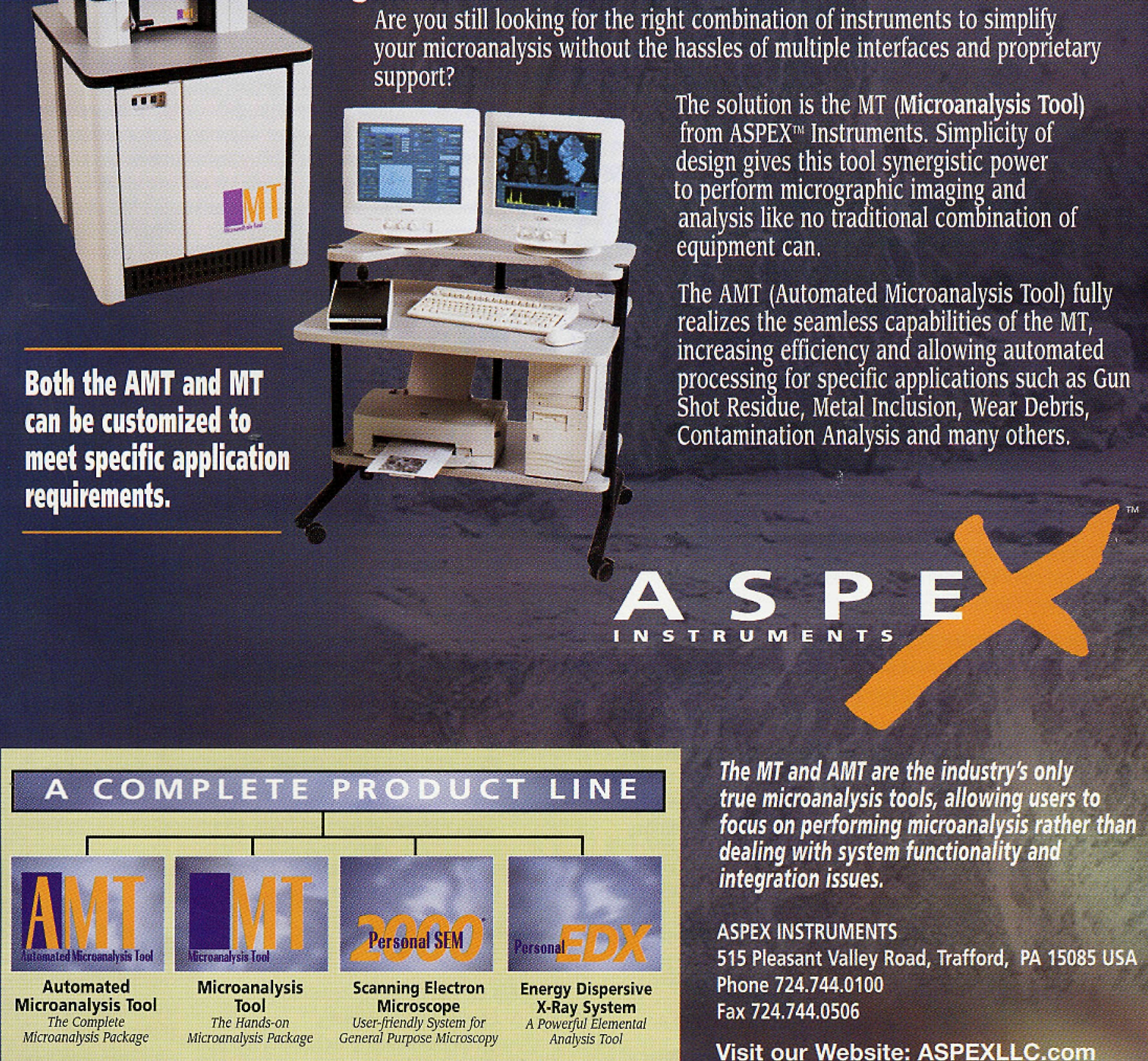

The MT and AMT are the industry's only true microanalysis tools, allowing users to focus on performing microanalysis rather than dealing with system functionality and integration issues.

ASPEX INSTRUMENTS

515 Pleasant Valley Road, Trafford, PA 15085 USA Phone 724.744.0100

Fax 724.744.0506

Visit our Website: ASPEXLLC.com 


\section{NAME CHANGES:}

The following Thermo Electric companies, in the next several months, will change their names as follows:

NORAN Instruments, Inc. to THERMO NORAN.

Nicolet Instruments Corporation to Thermo Nicolet.

Spectra-Tech, Inc. to Thermo Spectra-Tech.

The stated reason is to better reflect the larger Thermo Electron of which these companies are parts.

\section{MICROSCOPY \& MICROANALYSIS 2000 VIDEO}

Videotapes from M\&M 2000 are available for immediate shipment. Others, including the 2000 tapes, must be ordered from the video duplication service. This usually requires about two weeks. Please remember to order the tapes by number and title. Make checks payable to "MSA" in U.S. funds only. Purchase orders can be accepted. Orders may be placed by phone, mail, fax or eMail to the following.

Dr. Greg Erdos

University of Florida

Tel.: (352)392-1295

Biotechnology Program

Fax: (352)846-0251

PO Box 110580

Gainesville, FL 32611

If you are a presenter and would prefer not to have your tapes so offered, Please contact Dr. Erdos.

\section{RMC ELECTRON MICROSCOPY}

The RMC Electron Microscopy product line has been acquired by Boeckeler Instruments, Inc., a local Tucson high technology company, from Ventana Medical Systems.

The RMC product management group, including Dave Roberts, Greg Becker, Al Coritz and Gareth Morgan will stay with the RMC product line and continue to give support under the ownership of Boeckeler Instruments.

Boeckeler Instruments, Inc. Tel.: (520)745-0001

4650 South Butterfield Drive Fax: (520)745-0004

Tucson, AZ 85714 eMail: info@boeckeler.com

\section{NEWS RELEASE from MICROSCOPY/MARKETING \& EDUCATION (MME)}

MME recently conducted a mail-back study of 5000 materials scientists involved in semiconductor and industrial materials applications. With $2.5 \%$ responding (well within the expected $2-3 \%$ response rate), and an error range of approximately $+/-6 \%$, Microscopy Today was tied for second place (within error rate) with the prestigious R\&D as the publication on which these scientists relied most heavily when evaluating equipment for purchase.

Since ASM International, publishers of Advanced Materials and Processes, provided the list, the data contained an expected bias toward that publication.

Key rankings were as follows:

Advanced Materials \& Processes: $45 \%$

R\&D: $27 \%$

Microscopy Today: $21 \%$

Microscopy \& Microanalysis (MSA Journal): $11 \%$

Microscopy \& Analysis (A U.K. publication): $6 \%$

.... Barbara Foster, President, Microscopy/Marketing \& Education (c) www.MME-Microscopy.com/education

\section{SURPLUS EQUIPMENT}

Within the MSA listserver system, the Surplus Equipment URL is as follows:

http://www.msa.microscopy.com/SurplusEuipment/ SurplusListings.html 


\section{McCrone}

\section{Research}

\section{Institute...}

is a not-for-profit corporation dedicated to teaching and research in light microscopic analytical methods. The first intensive courses in industrial microscopy were started in 1952 in Chicago. We now teach about 50 individual courses each year with a staff of four full-time Professors. Most of the courses are five days long and are taught in our Chicago facility. Our intensive courses are designed to provide practicing scientists with training in polarized light microscopy. All of the courses provide an overview and emphasize the proper use of the microscope and its accessories. Other more specific courses are offered for chemists, biologists, criminalists, mineralogists, polymer chemists, art conservators, environmental quality experts, contamination control analysts and quality control specialists.

Each course has lectures, demonstrations and hands-on laboratory practice so that students learn each technique by hearing about it, watching it being done and then doing it. Closed circuit video is used extensively for lectures and classroom demonstration. Students learn powerful and effective methods for studying, characterizing and identifying materials of all kinds, and for rapidly solving research, production, and quality control problems.

We offer some of our courses nationally and internationally at academic, corporate and government laboratories.

\section{Microscopy CoURSES}

\section{Methods}

Applied Polarized Light Microscopy

Advanced Applied Polarized Light Microscopy*

Digital and Video Microscopy

Fluorescence Microscopy

Microchemical Methods*

Crystal Morphology and Optics

Particle Isolation, Manipulation and Mounting

for Additional Analysis

Chemical Microscopy and Polymorphism*

Advanced FTIR Microscopy

Microtome Methods

Conoscopy*

Scanning Electron Microscopy

\section{Forensic / Materials}

Forensic Microscopy

Advanced Forensic Microscopy (Trace Evidence)*

Forensic Hair and Fiber Microscopy

Microscopy of Illicit Drugs and Excipients*

Microscopy of Botanical Traces

Wood and Vegetable Fiber Microscopy

\section{Asbestos / Environmental}

Microscopical Identification of Asbestos

Advanced Asbestos Identification*

Indoor Air Quality: Microscopy of Fungal Spores, Pollen and House Dust

Asbestos Fiber Counting (NIOSH 582)

\section{Specialities}

Microscopy for Art Conservators

Pharmaceutical Microscopy

Polymer Microscopy

Pollen and Spore Identification

Microscopy of Food and Foreign Bodies Identification

Caking of Crystals

*Prerequisites: course 1201 (PLM)

or consent of instructor; $1608 \mathrm{~A}$ for $1608 \mathrm{~B}$

\author{
McCrone Research Institute \\ 2820 S. Michigan Avenue, Chicago, IL 60616 \\ Tel: 312/842-7100 Fax: 312/842-1078 \\ E-mail: ndaerr@mcri.org \\ http://www.mcri.org
}




\section{Goming atentrs}

YEAR 2000 McCRONE RESEARCH INSTITUTE SCHEDULE:

$\checkmark$ April 9/13: Advanced FTIR Microscopy

$\checkmark$ April 16/20: Electronic Imaging

$\checkmark$ April 23/27: Scanning Electron Microscopy

$\checkmark$ May 30/June 1: Fluorescence Microscopy

$\checkmark$ Sept. 5/7: Microtomy

$\checkmark$ Sept. 10/14: Advanced FTIR Microscopy

$\checkmark$ Sept. 24/26: Caking of Crystals

$\checkmark$ Nov. 5/9: Particle Isolation, Manipulation and mounting for Additional Analysis

$\checkmark$ Nov. 12/16: Scanning Electron Microscopy

For further information, contact Ms. Nancy Daerr: (312)842-7100, Fax: (312)842-1078, eMail: ndaerr@mcri.org

$\checkmark$ November 27/December '00: Scanning Electron Microscopy (McCrone Research Institute) Chicago, IL, Nancy Daerr, (312)842-7100, ndaerr@mcri.org

$\checkmark$ December $9 / 13^{~} 00$ : 40th Annual Meeting American Society for Cell Biology San Francisco, CA. www. ascb.org/ascb

$\checkmark$ January 20/26 101: Multiphoton Microscopy in the Biomedical Sciences (SPIE) San Jose, CA. http://spie.org/web/meetings/calls/ pw01/confs/BO31.html

$\checkmark$ February 25/28 '01: Contact Mechanics in Adhesion Science (The Adhesion Society) Williamsburg, VA, www adhesionsociety.org/

$\checkmark$ March 4/9 01: PITTCON 2001, New Orleans, LA. www.pittcon com

$\checkmark$ April 1/4 '01: Focus On Microscopy 2001, University of Amsterdam, The Netherlands. Www. focusonmicroscspy,org/

$\checkmark$ May 5/7 01: SCANNING 2001: (FAMS) New York City. Mary K Sullivan : (201)818-1010, scanning@fams.org

$\checkmark$ May 6/10 01: Modern Developments and Applications in Microbeam Analysis (EMAS), Tampere, Finland, www.emas.ac.uk/

$\checkmark$ May 13/16 01: Food Structure \& Functionality Symposium 2001, Minneapolis, MN. eMail: meeting@AOCS.org

$\checkmark$ May 21/25 01: FE-SEM and Image Analysis Courses Montreal Canada. Dr. Pierre Hovington: (450)652-8125, eMail: hovington. pierre@ireq.ca

\section{LEHIGH MICROSCOPY SCHOOL}

$\checkmark$ June 11/15 01: SEM and X-ray Microanalysis

$\checkmark$ June 10, '01: Introduction to SEM and EDS

$\checkmark$ June 18/22 '01: Advanced Scanning Electron Microscopy Quantitative X-ray Microanalysis

$\checkmark$ June 18/21'01: Analytical Transmission Electron Microscopy

$\checkmark$ June 19/21 '01: TEM Specimen Preparation

$\checkmark$ June 19/22 '01: Atomic Force Microscopy

For further information, contact Ms. Sharon Coe at: tel.: (610)7585133, fax: (610)758-4244, eMail: sharon.coe@lehigh.edu

$\checkmark$ June 18/21 '01: 17th Annual Short Course on Molecular Microspectroscopy (Miami University) Oxford $\mathrm{OH}$. (513)529-2874

$\checkmark$ July 2/6 01: 16th International Conference on X-ray Optics and Microanalysis (ICXOM XVI), Vienna, Austria, Www.icxom.at

$\checkmark$ Sept. 20/25 101: 5th Multinational Congress On Electron Microscopy. Lecce, Italy. Dr. Massimo Catalano, email: massimo. catalano@ime.le.cnr.it

$\checkmark$ Sept.30/Oct.4 '01: 2001 Eastern Analytical Symposium, Atlantic City, NJ, http://www.eas.org

$\checkmark$ August 4/9 '02: Microscopy \& Microanalysis 2002 (MSA/MAS) Quebec City, Canada, http://msc.rsvs.ulaval.ca

$\checkmark$ September 1/6 02: 15th International Congress on Electron Microscopy (ICEM-15). Durban, South Africa. Www.icem15.com

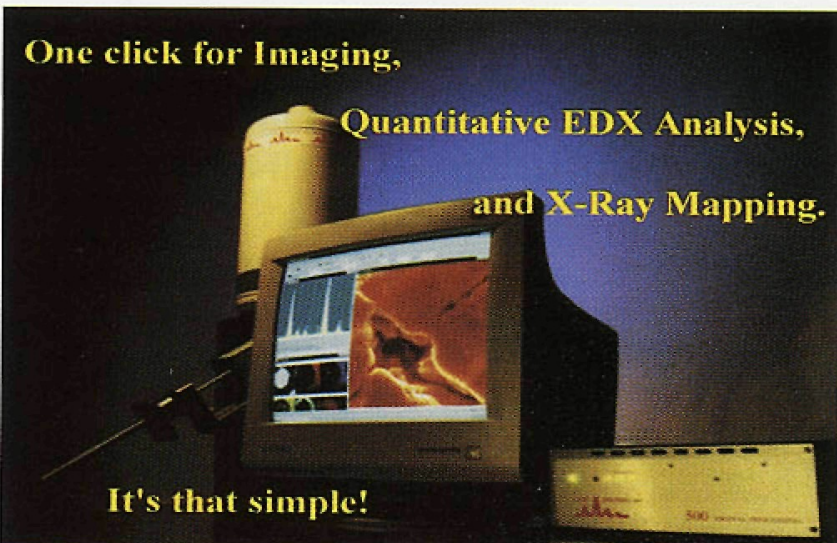

Digital Pulse Processing Electronics

High-Resolution Light-Element $\mathrm{Si}(\mathrm{Li})$ Detectors

High-Resolution Digital Imaging

Accurate and Fast Quantitative Analysis

Position-Indexed Spectroscopy

Automatic and Customized Particle/Feature Analysis Free Software Updates

Excellent Technical Support

Best Price/Performance Ratio in the Industry

Did we miss something? IXRF A SYSTEMS

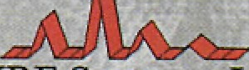

IXRF Systems, Inc.

15715 Brookford Drive

Houston, TX 77059

Tel: (281) 286-6485 Fax: (281) 286-2660 http://www.ixrfsystems.com

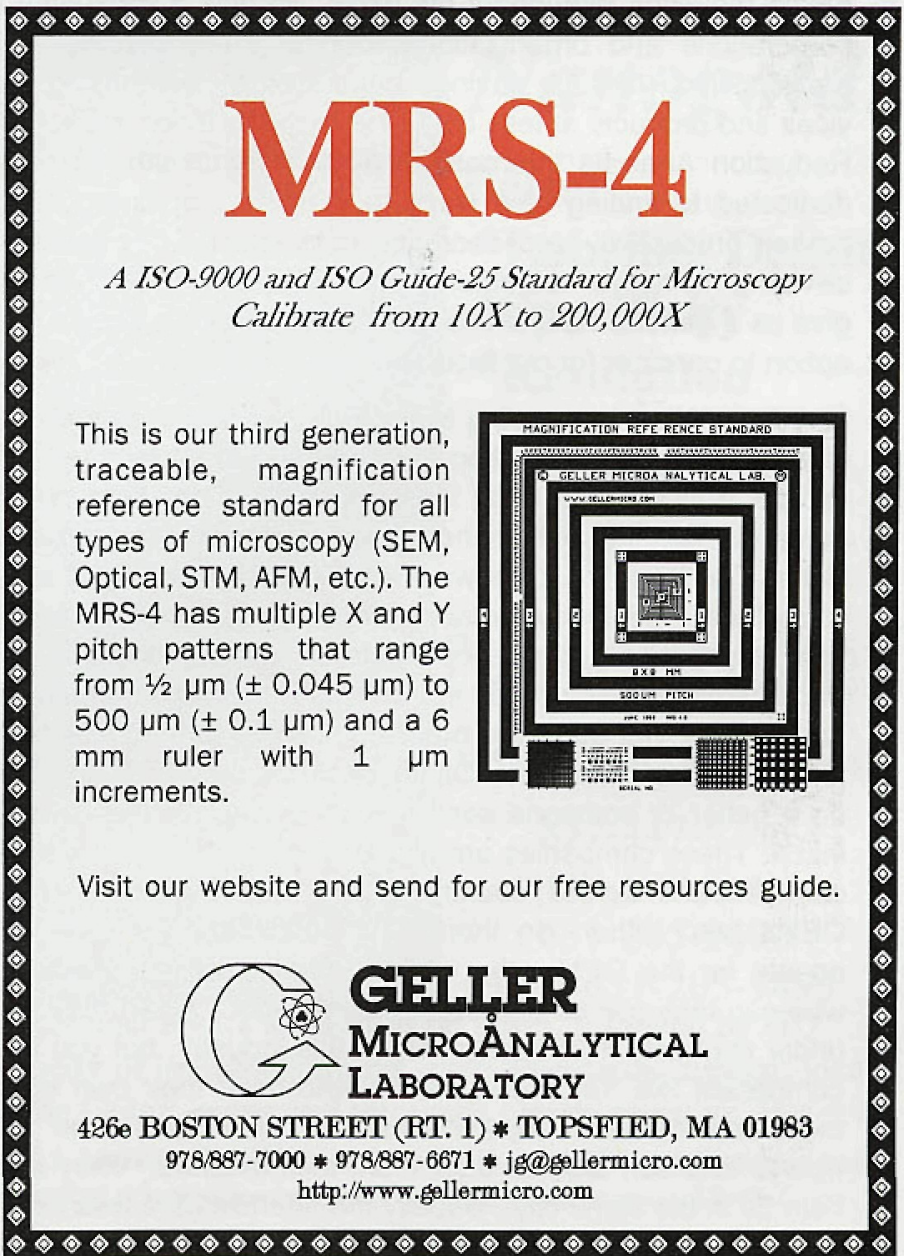

